\title{
Ion populations on open field lines within the dayside low-latitude boundary layer: theory and observations during a transient event
}

Article

Published Version

Lockwood, M. and Moen, J. (1996) Ion populations on open field lines within the dayside low-latitude boundary layer: theory and observations during a transient event. Geophysical Research Letters, 23 (21). pp. 2895-2898. ISSN 0094-8276 doi: https://doi.org/10.1029/96GL02761 Available at https://centaur.reading.ac.uk/38783/

It is advisable to refer to the publisher's version if you intend to cite from the work. See Guidance on citing.

Published version at: http://dx.doi.org/10.1029/96GL02761

To link to this article DOI: http://dx.doi.org/10.1029/96GL02761

Publisher: American Geophysical Union

All outputs in CentAUR are protected by Intellectual Property Rights law, including copyright law. Copyright and IPR is retained by the creators or other copyright holders. Terms and conditions for use of this material are defined in the End User Agreement. 


\section{CentAUR}

Central Archive at the University of Reading

Reading's research outputs online 


\title{
Ion populations on open field lines within the dayside low-latitude boundary layer: theory and observations during a transient event
}

\author{
M. Lockwood \\ Rutherford Appleton Laboratory, Chilton, Oxfordshire, UK.
}

\author{
J. Moen \\ The University Courses on Svalbard, UNIS, Longyearbyen, Svalbard
}

\begin{abstract}
We analyze of ion populations observed by the NOAA-12 satellite within dayside auroral transients. The data are matched with an open magnetopause model which allows for the transmission of magnetosheath ions across onc or both of the two Alfvén waves which emanate from the magnetopause reconnection site. It also allows for reflection and acceleration of ions of magnetospheric origin by these waves. From the good agreement found between the model and the observations, we propose that the events and the lowlatitude boundary precipitation are both on open field lines.
\end{abstract}

\section{Introduction}

The paper by Moen et al. [1996] presents observations of transient dayside auroral forms, seen from Svalbard in 630 $\mathrm{nm}$ light, within a region that simultaneous and conjugate observations of ion and electron fluxes by the NOAA-12 satellite define to be the low-latitude boundary layer (LLBL). The subsequent westward motion of the auroral forms is attributed to the tension force on newly-opened field lines and Moen et al. infer that the LLBL is on open field lines, at this time at least. They also review previous suggestions that the LLBL is open. Another recent paper, by Lockwood et al. [1996], has shown that the energetic magnetospheric ions which are a key part of the distinction between the precipitations classed as cusp and LLBL, can be generated on open field lines by reflection of the pre-existing magnetosphere population by the interior Alfvén wave. This wave is launched from the reconnection site into the inflow region, on the magnetospheric side of the boundary. The present paper uses the theory and model of Lockwood et al. to predict the ion fluxes seen by the NOAA-12 satellite.

\section{Theory}

Figure 1a illustrates the open LLBL, with two Alfvén waves (hereafter referred to as rotational discontinuities, RDs) emanating from the reconnection site, $X$, and standing in the inflow regions on the two sides of the boundary [from Lockwood et al., 1996]. For illustrative purposes, we consider magnetosheath plasma parameters at the X-line to be as in the case studicd by Lockwood et al. [1994], with a local Alfvén speed in the magnetosheath of $\mathrm{V}_{\text {Ash }}=190 \mathrm{~km} \mathrm{~s}^{-1}$. We

Copyright 1996 by the American Geophysical Union.

Paper number 96GL02761.

0094-8534/96/96GL-02761\$05.00 adopt a density $\mathrm{N}_{\mathrm{sp}}$ on closed field lines near the $\mathrm{X}$-line of $2.9 \times 10^{6} \mathrm{~m}^{-3}$ where the magnetic field $\mathrm{B}_{\mathrm{sp}}$ is $40 \mathrm{nT}$, giving an interior Alfvén speed $\mathrm{V}_{\text {Asp }}$ of $500 \mathrm{~km} \mathrm{~s}^{-1}$. The choice of these, and other, inputs will be discussed later. Because of a small field-aligned sheath flow at the X-line [Lockwood et al., 1994], the field line on the outer edge of the LLBL (the point $\mathrm{E}$ in figure 1a) moves along the exterior $\mathrm{RD}$ at $\mathrm{V}_{\mathrm{fe}}=$ $170 \mathrm{~km} \mathrm{~s}^{-1}$, which is close to $\mathrm{V}_{\text {Ash }}$. With no flow along closed field lines, the point I moves along the interior RD at the greater speed $\mathrm{V}_{\mathrm{fi}}=\mathrm{V}_{\mathrm{Asp}}=500 \mathrm{~km} \mathrm{~s}^{-1}$. Figure $1 \mathrm{~b}$ shows the velocity space construction used by Cowley [1982] to predict the particle distributions ( $\mathrm{t}$-sh and $\mathrm{r}$-sh) produced from the incident sheath population (i-sh) by, respectively, transmission through and reflection off the exterior RD at points like E. In addition, the magnetospheric ions (sp) are partially reflected off the magnetopause to produce a population called r-sp. This form of the construction is used and explained in greater detail by Lockwood [1995]. Cowley's theory has been shown to be very successful in predicting the distribution functions on both sides of the magnetopause [Gosling et al., 1990; Fuselier et al., 1991; Smith and Rodgers, 1991]. Recently, Lockwood et al. [1996] have found evidence for two components of the r-sp ions: one is produced by reflection off the interior $\mathrm{RD}$, here termed ri-sp; the other (re-sp) bcing transmitted through the interior RD (with negligible acceleration because the field rotation at $I$ is small so $\left.\theta_{i}+\phi_{i} \approx \pi\right)$ and subsequently reflected at the exterior $\mathrm{RD}$. The general velocity space construction for the interior $\mathrm{RD}$, is shown in Figure 1c. A key property of ideal-MHD RDs is that the peak of the distribution functions of all the populations are at the local $\Lambda$ lfvén speed in the rest framc of the field lines. The angles $\theta_{\mathrm{e}}$ and $\theta_{\mathrm{i}}$ are small near the $\mathrm{X}$ line so $\cos \left(\theta_{\mathrm{e}}\right) \approx \cos \left(\theta_{\mathrm{i}}\right) \approx 1$ and the peak phase space density of the re-sp population appears at $\left(\mathrm{V}_{\mathrm{Ash}}+\mathrm{V}_{\mathrm{fe}}\right)$ and that of the ri-sp population at $\left(\mathrm{V}_{\mathrm{Asp}}+\mathrm{V}_{\mathrm{fi}}\right)=2 \mathrm{~V}_{\mathrm{Asp}}$ in the Earth's frame. In addition, ions of the $\mathrm{sp}$ population moving away from the RI) at speed greater than the field line speed will fail to encounter the RD and so the ri-sp and re-sp populations are truncated at minimum velocities of $\mathrm{V}_{\mathrm{fi}}$ and $\mathrm{V}_{\mathrm{fe}}$, respectively. Because $\mathrm{V}_{\text {Asp }}>\mathrm{V}_{\text {Ash }}$ and $\mathrm{V}_{\mathrm{fi}}>\mathrm{V}_{\text {fe }}$, the ri-sp ions are considerably more accelerated than the re-sp and t-sh populations.

Using the theory of Cowley [1992], we can predict the spectra of all the populations: those for field-aligned (zero pitch angle) ions in the magnetosphere are given in figure 2. The dashed line is the injected sheath population, $\mathrm{t}$-sh, and is that deduced from low-altitude satellite data by Lockwood et al: [1994]. The dotted line is the magnetospheric population $\mathrm{sp}$ on closed field lines (and on those parts of open field 


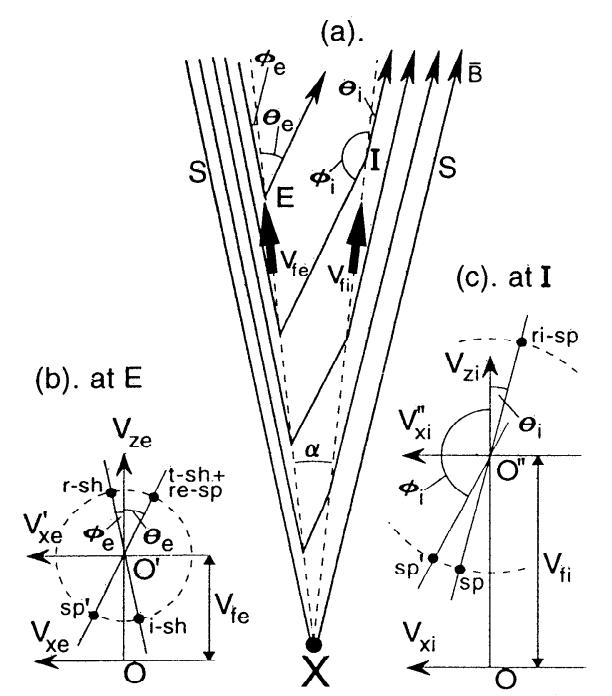

Figure 1. Schematic illustration of a simplified magnctopause reconnection layer produced by a reconnection site, $\mathrm{X}$. We consider only one interior and one exterior RD, standing respectively in the magnetosphere and magnetosheath inflow regions, shown in (a) as dashed lines which bound the reconnection layer (open $\mathrm{LLBL}$ ). The kinks in the newly-opened field lines at $\mathrm{E}$ and $\mathrm{I}$ propagate away from the $\mathrm{X}$ line at $\mathrm{V}_{\mathrm{fc}}$ and $V_{\mathrm{fi}}$, where $\mathrm{V}_{\mathrm{fi}}>\mathrm{V}_{\mathrm{fe}}$ (b) is the velocity-space construction for the point $\mathrm{E}$, on the exterior RD, as used by Cowley [1982]; (c) is the corresponding construction for the point I on the interior RD. See text for details [from Lockwood et al., 1996].

lines which have yet to encounter the interior RD), which we initially consider to be isotropic with concentration $\mathrm{N}_{\mathrm{sp}}$ and temperature $\mathrm{T}_{\mathrm{sp}}=8 \times 10^{7} \mathrm{~K}$. The solid line is the fraction $\mathrm{r}_{\mathrm{i}}$ (here taken to be 0.1 ) of the sp population which has been reflected off the interior RD (giving the ri-sp ions). Lockwood et al. [1994] found some evidence that there was some weak heating on interaction with the $\mathrm{RD}$ and this is here allowed for by raising the temperature of the ri-sp ions by a factor of $h_{i}=1.7$ over $T_{s p}$. The dot-dash line is the fraction $\left(r_{e}=0.1\right)$ of the sp population which has been reflected off the exterior RD (re-sp) with a heating factor of $h_{e}=1.5$ (allowing for two transmissions through the interior RD and a reflection off the exterior $\mathrm{RD}$ ). Also shown in figure 2 are three bands of ion energies, labelled 1,2 and 3. For each population, the integral flux in each band is computed by integrating the differential number fluxes shown in figure 2. The bands are the same as those monitored by the NOAA-12 satellite, namely $0.3-2.35 \mathrm{keV}, 30-80 \mathrm{keV}$ and $80-250 \mathrm{keV}$ (in fact, band 1 is produced by integrating over 3 separate energy ranges $0.3-0.458,0.773-1.088$ and $1.718-2.349 \mathrm{keV}$, but we here refer to this combination as $0.3-2.35 \mathrm{keV}$ ).

Figure 2 gives the populations of ions generated in the immediate vicinity of the $\mathrm{X}$-line only. Similar constructions can be made to predict the populations produced at subsequent times as the field line evolves away from the $\mathrm{X}$-line. In general, the precipitation seen at low-altitudes will be a convolution of these changing source populations with timeof-flight effects, as recently modelled for the t-sh population by Lockwood [1995]. However, a less complicated model of the precipitation seen by NOAA-12 can be made with one simplifying assumption: that the populations t-sh, ri-sp and re-sp do not depend on position, relative to the $\mathrm{X}$-line. In gencral, the highest energy ri-sp and re-sp ions will progressively be lost as the source sp ions are lost by interaction with the magnetopause. However, reflection off the RDs will scatter quasi-trapped $\mathrm{sp}$ ions at larger pitch angles, and this will act to prolong field-aligned re-sp and ri-sp fluxes. In addition, the interior RD will weaken with distance from the $\mathrm{X}$-line and the $\mathrm{t}$-sh population will vary with position because the sheath characteristics change and the field line accelerates. In this paper we are concerned only with features relatively close to the open-closed boundary and this assumption considerably simplifies the discussion. However, we do make some allowance for the loss of sp ions and the weakening interior RD by linearly reducing the reflection factor $r_{i}$ with time elapsed since reconnection. The importance of this approach is that it makes allowance for time-of-flight effects straightforward. It is possible to predict the population seen by a low-altitude satellite by simply truncating the spectra shown in figure 2 at a low-velocity time-of-flight cut-off. If the satellite, at a time $t_{s}$, observes a field line which was reconnected at a time $t_{0}$, the time elapsed since reconnection is $\left(t_{s}-t_{0}\right)$ and the ficld-aligned ions seen will have a minimum ("cut-off") energy of $(\mathrm{m} / 2)\left[\mathrm{d} /\left(\mathrm{t}_{\mathrm{s}}-\mathrm{t}_{\mathrm{o}}\right)\right]^{2}$, where $\mathrm{d}$ is the distance along the field line from the X-line to the altitude of the satellite [see Lockwood and Smith, 1994]. Thus for an assumed distance $d$, the parts of spectra t-sh, ri-sp and re-sp which have reached the satellite are known as a function of $\left(t_{s}-t_{0}\right)$ and the integral field-aligned fluxes in the energy bands 1,2 and 3 (see figure 2) can be calculated. Figure 3 shows the results for an assumed $d$ of $24 \mathrm{R}_{\mathrm{E}}$ (Earth radii). Note that the left hand edge of the plot at $\left(t_{s}-t_{0}\right)=0$ is the open/closed field line boundary and $\left(t_{\mathrm{s}}-\mathrm{t}_{\mathrm{o}}\right)>0$ is open field lines.

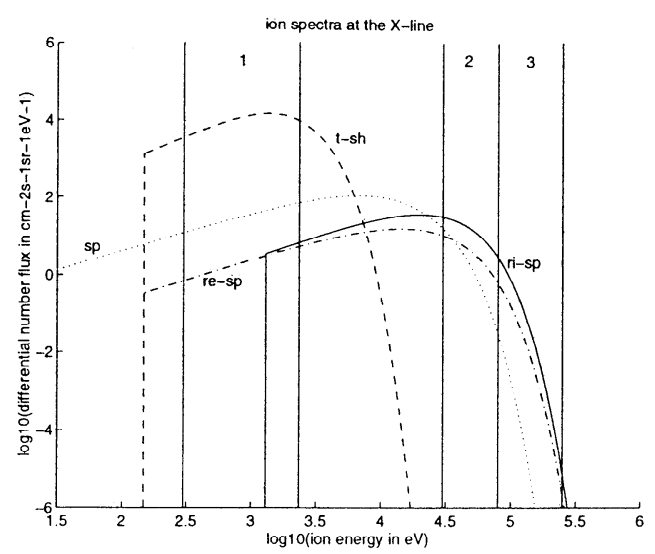

Figure 2. Field-parallel segments of the spectra of ions at the Xline, shown as differential number flux and as a function of the ion energy on a log-log scale. The dashed line is the magnetosheath population transmitted across the cxtcrior RD (t-sh), and the dotted line is the magnetospheric population on closed field lines $(\mathrm{sp})$. The solid line is that part of the sp population which is reflected off the interior RD (ri-sp) and the dot-dashed line that part reflected of the exterior RD (re-sp). The Alfvén speeds at the exterior and interior RDs are $\mathrm{V}_{\mathrm{Ash}}=190 \mathrm{~km} \mathrm{~s}^{-1}$ and $\mathrm{V}_{\mathrm{Asp}}$ $=500 \mathrm{~km} \mathrm{~s}^{-1}$. The density, temperature and speed of the peak distribution function of the $\mathrm{t}$-sh population are $1.2 \times 10^{7} \mathrm{~m}^{-3}$, $4.9 \times 10^{6} \mathrm{~K}$ and $355 \mathrm{~km} \mathrm{~s}^{-1}$, respectively, and the corresponding values for the $\mathrm{sp}$ ions are $2.9 \times 10^{6} \mathrm{~m}^{-3}, 8 \times 10^{7} \mathrm{~K}$ and zero. The density reflection factors for the $\mathrm{sp}$ ions at the exterior and interior RDs are $r_{c}=r_{i}=0.1$ and the corresponding field-parallel heating factors are $h_{c}=1.5$ and $h_{i}=1.7$. The bands marked 1 , 2 and 3 delineate the three energy channels of the NOAA-12 instruments used in figures 3 and 4. 

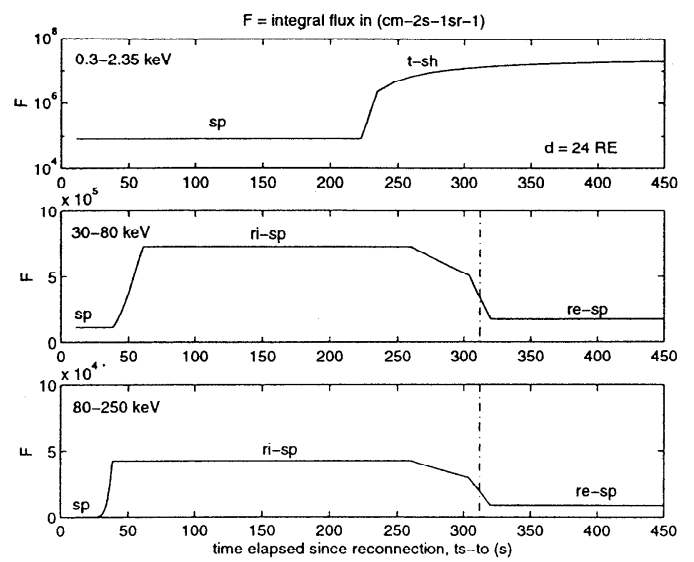

Figure 3. Modelled variations of integral ion flux over the cnergy bands $0.3-2.35 \mathrm{keV}, 30-80 \mathrm{keV}$ and $80-250 \mathrm{keV}$ (bands 1,2 and 3 in figure 2), as a function of time-elapsed since reconnection $\left(\mathrm{t}_{\mathrm{s}}-\mathrm{t}_{\mathrm{o}}\right)$. The field-aligned distance from the $\mathrm{X}$-line to the height of the satellite is taken to be $d=24 R_{E}$, and it is assumed that the characteristics defining all populations do not vary with distance from the reconnection site. The exception to this is $r_{i}$, which decreases linearly from 0.12 to 0.06 with increasing $\left(t_{\mathrm{s}}-\mathrm{t}_{\mathrm{o}}\right)$ after $260 \mathrm{~s}$ and before the arrival of the last ri$\mathrm{sp}$ ions at $306 \mathrm{~s}$ (the vertical dot-dash lines). The dominant ion population for each segment of each panel is marked.

In figure 3 , the population which dominates the integral ion flux is marked for the various segments of each curve. For small $\left(t_{s}-t_{0}\right)$, all three energy bands detect only the sp ions. At $\left(t_{\mathrm{s}}-\mathrm{t}_{\mathrm{n}}\right)=22.1 \mathrm{~s}, 250 \mathrm{keV}$ ions of the ri-sp population reach the satellite altitude for the first time and the integral flux in band 3 subsequently rises. At $\left(t_{s}-t_{0}\right)=38 \mathrm{~s}$, the lowenergy cut-off has dropped to $80 \mathrm{keV}$, and so the rise in fluxes in energy band 3 ceases and that in band 2 begins: these subsequently plateau at $64 \mathrm{~s}$ when the cut-off energy drops below $30 \mathrm{keV}$. At $\left(\mathrm{t}_{\mathrm{s}}-\mathrm{t}_{\mathrm{o}}\right)=228 \mathrm{~s}$, the cut-off energy falls to $2.35 \mathrm{keV}$ and fluxes in band 1 begin to rise. Figure 2 shows that these will be dominated by the t-sh population: initially they will be super-Alfvénic ions, which have passed through and are running ahead of the interior wave. For a constant Alfvén speed, the interior wave arrives at the satellite altitude at $\left(t_{s}-t_{0}\right)=306 \mathrm{~s}$ : once the satellite is poleward of the point where the wave arrives, it can no longer see the ri-sp population and only lower-flux re-sp ions would be seen at high energies in bands 2 and 3 (figure 2). However, in reality, the wave will accelerate and so it will overtake some of the ri-sp ions it had previously generated and will arrive before the transition from ri-sp to re-sp (the step down in fluxes seen by bands 2 and 3 at $\left(t_{s}-t_{0}\right)=306 s$, marked by the vertical dot-dash lines). In the interval $\left(\mathrm{t}_{\mathrm{s}}-\mathrm{t}_{\mathrm{o}}\right)$ $=260-306 \mathrm{~s}$, the ri-sp fluxes in bands 2 and 3 decay because of the decrease in $r_{i}$, imposed to simulate the weakening of the RD and the progressive loss of $\mathrm{sp}$ ions.

Figure 3 predicts a region of high fluxes of high-energy ions, poleward of the open/closed boundary and straddling the equatorward edge of the injected sheath precipitation. Most satellites do not fly in such a way that $\left(\mathrm{t}_{\mathrm{s}}-\mathrm{t}_{\mathrm{o}}\right)$ is a simple function of observation time $t_{\mathrm{s}}$. This means that the underlying structure predicted in figure 3 will be complicated by many factors, including boundary motions due to timevarying reconnection. In the next section, we use the model to show that the satellite data presented by Moen et al. [1996] are consistent with such motions and an open LLBL.
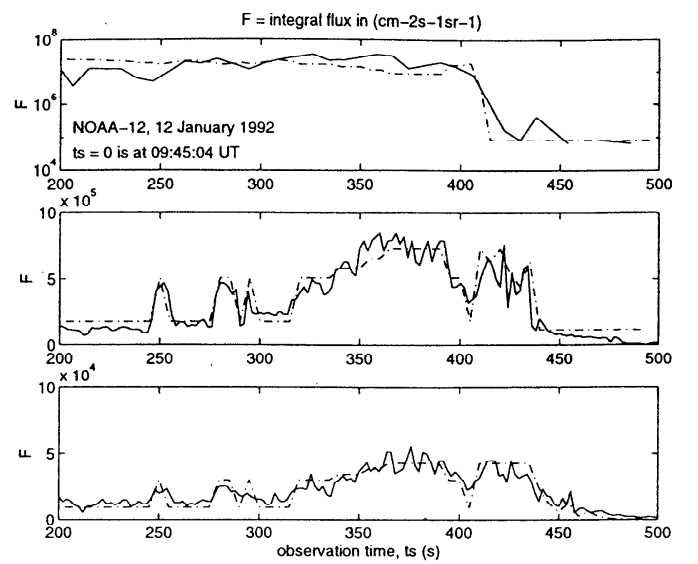

Figure 4. Observed (solid lines) and modeled (dot-dash lines) integral ion fluxes in the three energy channels used in figures 2 and 3 , as a function of $t_{s}$, the time of the observations by NOAA-12 on 12 January $1992\left(t_{s}=0\right.$ is $09: 45: 04$ UT).

\section{Observations on 12 January 1992}

Figure 4 presents the fluxes observed in channels 1, 2 and 3 by the NOAA-12 satellite on 12 January 1992. The data are shown as a function of time $t_{s}$ by solid lines, with model fits produced from figure 3 as dot-dash lines $\left(t_{s}=0\right.$ is defined as 09:45:04 UT). The fits were produced by varying $\left(t_{s}-t_{0}\right)$, the time elapsed since reconnection, at each $t_{s}$ but with no changes to any of the parameters used to generate figure 3. The best-fit variation of $\left(\mathrm{t}_{\mathrm{s}}-\mathrm{t}_{\mathrm{o}}\right)$ with $\mathrm{t}_{\mathrm{s}}$ is shown in figure 5 , for the assumed $d$ of $24 R_{E}$. Note that the assumed $d$ only changes the $\left(t_{s}-t_{0}\right)$ axis in figure 5 and does not influence figure 4 . It can be seen that the agreement is very good and we conclude that the observed particle distributions are consistent with the populations predicted here on open field lines. The underlying structure (seen in figure 3) is moved back and forth across NOAA-12, giving the observed variation with $t_{s}$. Specifically, at $t_{s}=200 \mathrm{~s}$, the satellite is observing field lines opened $\left(t_{s}-t_{0}\right)=380 \mathrm{~s}$ earlier. At this time, the $t$-sh population is seen in band 1 , whereas the re-sp population is detected in bands 2 and 3. As it flies equatorward (slowly because of the quasi-longitudinal nature of the pass) the satellite encounters generally lower $\left(t_{s}-t_{0}\right)$. However, this fall is not smooth and the fluctuations mean that the satellite intersects the step change at $\left(t_{s}-t_{0}\right)=306 \mathrm{~s}$ several times. This is reflected in jumps seen in bands 2 and 3: the higher fluxes being the ri-sp population. Between $t_{s}=325$ and 390s the ri-sp fluxes in bands 2 and 3 rise because the factor $r_{i}$ is increased with decreasing $\left(t_{s}-t_{0}\right)$. The small rise in $\left(t_{s}-t_{0}\right)$ before $t_{s}=400 \mathrm{~s}$ allows the step to pass once more

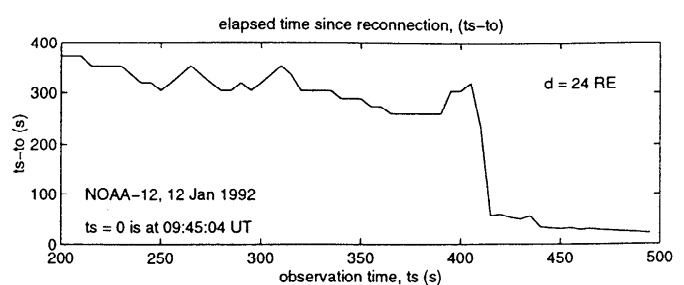

Figure 5. Variation of time-elapsed since reconnection $\left(t_{\mathrm{s}}-\mathrm{t}_{\mathrm{o}}\right)$ with observing time, $t_{s}$, used to generate the model data shown in figure 4. The $\left(t_{s}-t_{0}\right)$ scale assumes that the field-aligned distance $d$ from the $X$-line to the height of the satellite is $24 R_{E}$. 
equatorward over the satellite, before a major decrease in $\left(t_{s}-\right.$ $t_{\mathrm{o}}$ ) at $\mathrm{t}_{\mathrm{s}}=405-415 \mathrm{~s}$ when the satellite enters a newer transient event. This decrease causes the t-sh population to vanish from band 1 (i.e. the satellite has passed through the ion edge of the injected population for the first time [Gosling et al., 1990]). Note that the ri-sp population is still seen after this time but time-of-flight effects cause fluxes to decline in band 2 and then in band 3 as $\left(t_{\mathrm{s}}-\mathrm{t}_{\mathrm{o}}\right)$ slowly decreases and the satellite approaches the open/closed boundary. By the end of the plot only the sp population is seen. Initially this is on open field lines (that are so recently reconnected that even the ri-sp ions in band 3 have not had time to reach NOAA12) but continues as the satellite crosses the poleward edge of central plasma sheet (CPS) electrons (at $t_{s}=422$ s, i.e. 09:52:06 UT) and subsequently onto closed field lines.

The step around $t_{s}=410 \mathrm{~s}(09: 51: 54 \mathrm{UT})$ corresponds to the motion of the satellite from one event into that produced by a later reconnection pulse. Allowing for the $110 \mathrm{~s}$ delay in the $630 \mathrm{~nm}$ emission, the satellite passed through the equatorward edge of one observed transient event at this $t_{s}$, into a region that subsequently developed into another: as it did so, it detected a major decay in the flux of the sheathlike electrons responsible for most of the luminosity [Moen et al., 1996]. Thus the best explanation of the step-like change in $\left(t_{s}-t_{0}\right)$ seen in figure 5 is that the reconnection rate was pulsed, the step arising from a period of low reconnection rate between the pulses, as predicted by Lockwood and Smith [1994]. For the illustrative $d$ of $24 \mathrm{R}_{\mathrm{E}}$, this period of slower reconnection would have lasted for about (340-60) $=$ $280 \mathrm{~s}$, which is consistent with the periods between the transient $630 \mathrm{~nm}$ auroral transients observed in the LLBL.

\section{Discussion}

The importance of the observations modeled here is that they clearly demonstrate a population of accelerated magnetospheric ions poleward of the poleward edge of the central plasma sheet electrons and straddling the ion edge of injected magnetosheath ions. Fnergy bands 2 and 3 show enhanced fluxes in this region, greater than those both equatorward and poleward of the region. Therefore this population cannot be an extension of the CPS to higher latitudes, but there must be some process generating the higher fluxes observed at the higher energies. Thus it is not adequate to invoke the extension of ion trapping onto open field lines. We here have shown that such a population is to be expected in the open magnetosphere model and arises from acceleration (and possibly some weak heating) of the CPS population by reflection off the interior Alfvén wave generated by the reconnection site. The LLBL is then a mixture of this (ri-sp) and the injected sheath (t-sh) populations.

The data do reveal the limitations of the assumption that the ion source characteristics do not change with distance from the reconnection site. In particular, the fluxes in the t-sh population seen in band 1 gradually decay with increasing latitude (lower $t_{s}$ ) in figure 4 , an effect expected because sheath densities decay while the field line evolves away from the nose of the magnetosphere. The parameters used to predict the populations in figure 2 are illustrative and intended to demonstrate the potential of the model for explaining the observations, they do not represent the best possible fits to the data. In particular, Lockwood et al. [1996] found that $\mathrm{N}_{\mathrm{sp}}$ at the magnetopause is likely to be bigger than discussed here because the ion measurements at low altitudes are only the loss cone of a non-isotropic magnetospheric population. The main effect of a larger $\mathrm{N}_{\mathrm{sp}}$ is to reduce the temperatures of the re-sp and ri-sp populations required to fit the data. This means that either the heating factors $h_{i}$ and $h_{e}$ and/or the temperature of the initial sp population may be smaller than used here. The $\mathrm{T}_{\mathrm{sp}}$ of $8 \times 10^{7} \mathrm{~K}$ employed is indeed rather high, but was chosen to match the ion fluxes seen at $t_{s}=440 \mathrm{~s}$, near the poleward edge of the CPS, as defined from the electron data (at $t_{s}=422 \mathrm{~s}$ ). The ion flux seen in band 2 does subsequently decrease below that for the adopted $\mathrm{sp}$ population, indicating that $\mathrm{T}_{\mathrm{sp}}$ does indeed decrease as the satellite moves deeper into the CPS.

Acknowledgements. This work was carried out during a visit to Svalbard by ML as part of the UNIS guest lecturer scheme. We also thank D. Evans for the provision of the NOAA-12 data.

\section{References}

Cowley, S. W. H., The causes of convection in the Earth's magnetosphere: A review of developments during IMS, Rev. Geophys., 20, 531-565, 1982.

Fuselier, S.A., et al., Ion reflection and transmission during reconnection at the Earth's subsolar magnetopause, Geophys. Res. Lett., 18, 139-142, 1991.

Gosling, J.T., et al., The electron edge of the low-latitude boundary layer during accelerated flow events, Geophys. Res. Lett., 17, 1833-1836, 1990.

Lockwood, M., The location and characteristics of the reconnection $\mathrm{X}$-line deduced from low-altitude satellite and ground-based observations: 1. Theory, J. Geophys. Res., 100, 21791-21802, 1995.

Lockwood, M., et al., Ion acceleration at both the interior and exterior Alfvén waves associated with the magnetopause reconnection site: signatures in cusp precipitation, J. Geophys. Res., in press, 1996.

Lockwood, M., et al., The characteristics of the magnetopause reconnection $\mathrm{X}$-line deduced from low-altitude satellite observations of cusp ions, Geophys. Res. Lett., 21, 27572760, 1994.

Lockwood, M., and M.F. Smith, Low- and mid-altitude cusp particle signatures for general magnetopause reconnection rate variations: I - Theory, J. Geophys. Res., 99, 8531-8555, 1994.

Moen, J., et al., Dayside moving auroral transients related to LLBL dynamics, Geophys. Res. Lett., in press, 1996.

Smith, M.F. and Rodgers, D., Ion distributions at the dayside magnetopause, J. Geophys. Res., 95, 11617-11624, 1991.

M. Lockwood, RAL, Chilton, Didcot, OX11 0QX, UK. (email: m.lockwood@rl.ac.uk)

J. Moen, UNIS, PO Box 156, N-9170, Longyearbyen, Svalbard, Norway (e-mail: jmoen@unis.no)

(Received: March 25, 1996; revised, June 13, 1996; accepted: June 18, 1996.) 